\title{
Predicting students' final grades for regulating the supervision of academic activities: A model of continuous assessment practices, teaching effectiveness and students' personal studies
}

\author{
Monday Ugiagbe Agbonkpolo*, Thaddeus Ifeanyi Mamah, Bridget Oyamendan \\ Department of Education, Faculty of Arts and Education, Benson Idahosa University, \\ Benin City, Edo State, Nigeria. \\ *Corresponding author: magbonkpolor@biu.edu.ng
}

\begin{abstract}
Received: 04 April 2020; Accepted: 24 April 2020; Published: 28 April 2020
To cite this article (APA): Agbonkpolo, M. U., Mamah, T. I., \& Oyamendan, B. (2020). Predicting students' final grades for regulating the supervision of academic activities: A model of continuous assessment practices, teaching effectiveness and students' personal studies. Asian Journal of Assessment in Teaching and Learning, 10(1), 51-58. https://doi.org/10.37134/ajatel.vol10.1.6.2020
\end{abstract}

To link to this article: https://doi.org/10.37134/ajatel.vol10.1.6.2020

\begin{abstract}
The study was conducted to determine the predictive strength of a model of continuous assessment practices, teaching effectiveness and students' personal studies for predicting students' final grades. Thus the study investigated the influence of continuous assessment practices, teaching effectiveness, and students' personal studies on the test scores of some selected junior secondary school students in Health and Physical Education in Egor Local Government Area of Edo State. Three null hypotheses were formulated to guide the study. The hypotheses were tested at 0.05 level of significance. The population of the study was 4,042 while the sample size was 200 randomly selected from JSS III in Egor LGA of Edo State. The instrument used for data collection was the questionnaire with reliability co-efficient of 0.89. Data collected were analyzed using the Pearson Product Moment Correlation Statistics and the multiple regression statistics. The major findings of this study were are as follows: The multiple regression coefficient of prediction of students' final grade with ratings of continuous assessment practices, teaching effectiveness and students' personal studies is significant $(\mathrm{R}=0.65$, $\mathrm{p} \leq 0.00$ ). The net regression coefficient of prediction of students examination grades with ratings of continuous assessment practices is positive and significant $(B=0.54, p \leq 0.00)$. The net regression coefficient of prediction of students final grades with ratings of students personal studies is positive and significant $(\mathrm{B}=0.31, \mathrm{P} \leq 0.00)$. The net regression coefficient of prediction of students' final grades with ratings of teaching effectiveness is positive and significant at 0.05 alpha level $(B=0.46, p \leq 0.00)$. It was, therefore, recommended that the ministry of education and school administrators adopt the use of this scientific model to predict students' final grades, for regulating the supervision of teaching and learning process for optimization of students' academic achievement.
\end{abstract}

Keywords: Continuous Assessment Practices, Teaching Effectiveness, Students' Personal Studies, Final Grades

\section{INTRODUCTION}

One of the most important and significant developments in Nigerian educational system of recent was the introduction of the use of Continuous Assessment (CA) in evaluation of pupils and students at all levels of schooling. By implication, every teacher from primary to secondary level of education should understand and practice CA. National Policy on Education (NPE) (Federal Republic of Nigeria, 2013) observed that the existing practice (in most institutions of learning) of basing the assessment of students work on final examination and on one-short examination only is no longer tenable.

The history of the introduction of CA in Nigeria's NPE dated back to the 1969 curriculum development conference in a paper presented by the Nigerian Educational Research Council (NERC, 1983). The NPE (Federal Republic of Nigeria, 1981) stated that: "Ultimately, there will be no formal examination at the end of the first six years of primary education; certificate will be based on continuous 
assessment." At the end of first three years following primary education, the junior secondary school certificates will be based on final examination and continuous assessment. The certificate will be issued by the head of the institution. At the end of the senior secondary school work, a formal examination will be given but the performance during the three years will be weighted and taken into account for certificate purpose. The university and other institutions of higher learning where not left out in use of continuousassessment. The emphasis on CA is not limited to Nigeria alone; other African countries notably Kenya, Zambia, Ghana, and Liberia have adopted the same policy.

According to Obanya (1985), assessment involves the systematic collection of data on all aspects of an educational endeavor. This means that the data collected about students' academic achievement is used on a continuous basis in a systematic way, to take meaningful decisions on what should happen. Mwebaza (2010) have also indicated that, in the global context, assessment of students achievement is changing, most essentially as a result of the ever-changing knowledge based society, students are not only required to learn and understand the basics but also to think outside the box, to analyze, and to make inference for decisions purposes. It is therefore critical that continuous assessments utilize strategies that are able to measure the changing students' abilities and attitudes, According to Onuka (2006), there is a need to use a variety of instruments to effectively measure the students' traits. And the results are used to assist the students to improve themselves. In addition, Lewin (2001) reported that, over the years, various attempts have been made in many countries to improve the quality of examinations through the continuous assessment provisions. For example, in Tanzania, the National Examination Council for Tanzania (NECTA) in the late 1970s established continuous assessment programs to monitor students' academic progress in the whole education cycle from lower classes to higher classes. Thus, Webb \& Briars (1990) opined that assessment must be an interaction between the teacher and students, with the teacher continually seeking to understand, what a student can do and how a student is able to do it

Indeed, in secondary schools, assessment of students' learning in the classroom has been an integral component of the teaching-learning process especially at A- level because there is much effort by the teachers to teach a lot of contents to students. However, to Kellaghan \& Greany (2003), that kind of assessment is subjective, informal, immediate, ongoing and intuitive as it interacts with learning as it occurs. Although according to them, the main argument behind the adoption of continuous assessment is to avoid focusing all efforts, time and energy on just one exam, this is not true in Uganda's, A- level schools. Teachers and students put their focus on final examinations called Uganda Advanced Certificate of Education Examinations (UACE). This is because UACE results are an important determinant of future opportunities for higher education and other life chances.

Teachers' assessment of students' learning in the classroom plays a central role in the learning process of all students, because through the continuous assessment practices, students' progress is continuously assessed. This can affect the final results of the students in two ways: The first is by the percentage it accounts for on the overall student assessment. This percentage weight of continuous assessment varies according to administrative policies. In literature, the percentage weight of continuous assessment ranged from $10 \%$ to $60 \%$ or even being the single method of assessment without final results (Kaddam \& Elnimeiri, 2012). The second is the students overall achievement due to the influence of the practice of continuous assessment on teaching effectiveness and students' personal studies. This second dimension is the focus of this study. Trottera (2006) revealed that continuous assessment encourages students to learn in an ongoing basis. This manner of learning provides a feedback to the students about their learning and enables teachers to know the areas of strength and weakness of the learners, and intervene. Thus continuous assessment includes all strategies implemented by teachers to ascertain the knowledge, the understanding and skills gained by students. In other words, continuous assessment is the frequent interactions between teachers and students that enable teachers to know the strength and weakness of the learners. What has empirical studies in literature shown about the impact of continuous assessment?

Shoukat et al. (2013) conducted a research titled factors contributing to the Students Academic Performance: A Case Study of Islamia university sub-campus. The Purpose of the study was to investigate the factors affecting academic performance of graduate students of Islamia university of Bahawalpur Rahim Yar Khan Campus. The linear model of graduate students' performance was designed. The data were collected from 100 students through separate structured questionnaire from different departments in the campus. The study shows that students' personal study which is hinged on the study hour and tutorials exacts $31 \%$ variations in academic performance. The coefficient of the study hours and tutorials according 
to the researchers shows that a unit increase in study hours and tutorials causes an increase in academic performance by 2.66 , holding other factors as constant. This is significant at 0.05 alpha level. Thus they concluded that study time and tutorials are the most important factors affecting the student scores. According to the study, the correlation strength among test scores, study hours and tutorials are positive. Study hours and tutorials collectively represent students' personal studies. The implication of this percentage impact of students' personal studies is that $69 \%$ of the variation in the students' performance is attributable to other factors such as teaching effectiveness, continuous assessment practice, innate potentials and the test itself. The influence of the assessment tools is the focus of the study carried out by Laurent (2011).

Laurent (2011) conducted a research titled: The influence of continuous assessment tools on students' academic performance in chemistry for ordinary level secondary education in Tanzannia. The study aimed at examining the influence of continuous assessment tools on academic performance among high and low performing secondary schools in Tanzania. The quantitative and qualitative research methods were employed; the instruments used involved interview schedule, questionnaire, and focus discussion group schedule. The sample consisted of 259 participants involving 229 students, 24 teachers and 6 head of schools. This was obtained through purposive sampling technique. The study revealed that continuous assessment practices from the high performing secondary schools engendered a high level of analytical skills as result of time devoted by students on personal studies and regular practical exercises. The students from the low performing secondary schools were not assessed continually, which consequently hampered the development of analytical skills and the students' drive for personal studies. How do these attributes impact on the students final results?

Rezigalla et al. (2014) conducted a research titled: The impact of continuous assessment on final results, a case study of college of medicine, King Khalid University. The aim was to study the effect of continuous assessment on final result of students. The study design was a retrospective cross-sectional type and students' scores were obtained from students' results of the continuous assessment, final assessment and final result. Two samples were used, first sample was 61 students in 2012-2013 academic section and the second sample was 83 students in 2013-2014 academic section. The study showed that both continuous assessment and final assessment have high levels of correlation with the final result. Correlation coefficient was higher between continuous assessment and final assessment than between final assessment and final result. The t-test showed a significant difference between final assessment and the final result. The study made the following conclusions: that continuous assessment has an impact on both the students' results and their methodologies of learning. And that serious attention should be directed towards the tools that are used in the continuous assessment. Furthermore, that training of teachers in both exam settings and implementation is important as they have direct impact on the methodology of assessment. Methodologies of learning as used by the researchers most probably refer to students personal studies. So if students' personal studies are positively influenced, all things being equal, will in turn impact on their final examination scores. Similarly, Arribas (2012) also showed that continuous assessment scores have high level correlation with final examination scores.

In the same vein, Joe (2010) carried out a study, titled: the effect of continuous assessment on academics performance of students in home economics in secondary schools in Fegge in Onitsha South Local Government Area of Anambra State. The study aimed to investigate what is really meant by continuous assessment and weather it has any positive or negative effect on academic performance of students in Home Economics. The study also went further to find out the challenges of the teachers and students with continuous assessment and their attitude towards the implementation. The study used structured questionnaire (open and close ended) to collect data and a sample size of 140 students and 20 teachers.

The study revealed that continuous assessments have high positive percentage impact on academic performance of students in Home Economics in secondary schools. The students performed well in the Home Economics and this performance was attributed to the continuous assessment and effective teaching. Based on these findings, the study affirmed that continuous assessment and instructional materials play a vital role in students' academic performance in secondary schools. Therefore the paper concluded that adequate use of instructional materials and proper methodology by teachers will enhance good understanding of home economics. Therefore, the foregoing means that continuous assessment, teaching effectiveness and students personal studies could be used to predict student' performance in the final examinations.

The aforementioned studies showed that there is significant correlation among continuous 
assessment, students' personal studies, teaching effectiveness and students' final assessment scores. The pilot study carried out in this study shows that continuous assessment practice per se significantly influences the continuous assessment scores. Therefore continuous assessment practice could be used in the place of continuous assessment scores to predict students' final examination scores. This model has direct administrative relevance since the practice of continuous assessment can be regulated and supervised unlike the CA scores which cannot be directly influenced because they represent the outcome. To achieve a desired result (target examination scores) administrators would use the model to regulate and supervise the continuous assessment practice, teaching methodology and indirectly fine-tune students' personal studies.

This study was therefore carried out to assess the strength of the model of continuous assessment practices, teaching effectiveness, and students' personal studies in predicting students' performance in final examination using health and physical education students in selected schools in Oredo Local Government Area in Edo State, with the following specific objectives to (1) assess the relationship between pairs of continuous assessment practices, teaching effectiveness, students personal studies and students final grades; (2) assess the strength of the model of continuous assessment practices, teaching effectiveness and students personal studies, for predicting the students' final grades; and (3) assess the strength of the individual coefficients of continuous assessment practices, teaching effectiveness and students' personal studies, for predicting the students' final grades.

\section{HYPOTHESES}

The following null hypotheses were formulated and tested at 0.05 level of significance.

$\mathrm{Ho}_{1}$ There is no significant relationship between pairs of continuous assessment practices, teaching effectiveness, students' personal studies and students' final grades.

$\mathrm{Ho}_{2}$ The multiple regression model of continuous assessment practices, teaching effectiveness and students' personal studies does not significantly predict students' final grades.

$\mathrm{Ho}_{3}$ The individual coefficients of continuous assessment practices, teaching effectiveness and students' personal studies in the multiple regression model does not significantly predict students' final grades.

\section{METHODOLOGY}

Correlational research design was use in the study. It was aimed at determining the strength of the model of continuous assessment practices, teaching effectiveness and students' personal studies in predicting students' final grade in selected public junior secondary students III in health and physical education in Egor Local Government Area. The population for the study consisted of 4,042 JSS III students in 13 public schools in Egor Local Government Area, Ministry of Education, Edo State. The sample size for the study was 200 which was arrived at using Taro Yamane sampling formula (Yamane, 1967). The questionnaire was administered to 40 JSS III students in JSS II Health and Physical Education class at random in each of the five public secondary schools in Egor Local Government Area.

The research instrument used for study was the structured questionnaire which consisted of four sections which were constructed by the researchers to obtain information relating to the objectives of the study. Section A seeks information on the continuous assessment practices. Section B seeks information on the teaching effectiveness of teachers; Section C seeks information on the students' personal academic studies. Section D seeks information on the students' final grade.

Two experts in field of psychology and educational evaluation vetted the instruments and their corrections were effected before proceeding to the field. The reliability of the instrument was tested using test retest method, by administering the instrument twice in one week interval to 40 junior secondary school students within the study population but outside the selected sample. The result of the reliability was 0.89 which shows that the instrument was reliable. The questionnaire was administered by the 
researchers and a teacher who served as research assistant. He was briefed on how to administer the questionnaire. The researchers obtained permission from the principals. The items in the questionnaire were explained to the respondents. 200 questionnaires were distributed and all were retrieved and were properly filled. The instrument's measurement level was the interval scale, Section A-C, was measured as follows: Excellent $=5$, Very good $=4$, Good $=3$, fair $=2$, poor $=1$; while section D which was on the students' final result was measured as follow: $\mathrm{A}=5, \mathrm{~B}=4, \mathrm{C}=3, \mathrm{D}=2, \mathrm{E}=1$. Pearson Product moment correlation statistics was used to test hypothesis 1 while the multiple regression statistics was used to test the hypotheses 2 and 3 at 0.05 level of significance.

\section{PRESENTATION OF THE SUMMARY OF THE TEST OF HYPOTHESES}

The summary of the test of hypotheses are presented as follows:

\section{Hypothesis 1}

There is no significant relationship between pairs of continuous assessment practices, teaching effectiveness, students' personal studies and students' final grades. The summary of the analysis of data in respect of this hypothesis is presented in Table 1.

Table 1: Pearson Product Moment Correlation coefficients between pairs of continuous Assessment practices, teaching effectiveness, students' personal studies and students' final grades.

\begin{tabular}{|c|c|c|c|c|c|}
\hline & & $\begin{array}{c}\text { Continuous } \\
\text { assessment } \\
\text { practice }\end{array}$ & $\begin{array}{c}\text { Teaching } \\
\text { effectiveness }\end{array}$ & $\begin{array}{c}\text { Students } \\
\text { personal } \\
\text { studies }\end{array}$ & $\begin{array}{c}\text { Students' } \\
\text { final grade } \\
\text { points }\end{array}$ \\
\hline \multirow{3}{*}{$\begin{array}{l}\text { Continuous Assessment } \\
\text { practices }\end{array}$} & Pearson $r$ & & $.673^{* *}$ & $.536^{* *}$ & $.414^{* *}$ \\
\hline & Sig. (2-tailed) & & .000 & .000 & .000 \\
\hline & $\mathrm{N}$ & & 200 & 200 & 200 \\
\hline \multirow[t]{3}{*}{ Teaching effectiveness } & Pearson $\mathrm{r}$ & $.673^{* *}$ & & $.560^{* *}$ & $.251^{* *}$ \\
\hline & Sig. (2-tailed) & .000 & & .000 & .000 \\
\hline & $\mathrm{N}$ & 200 & & 200 & 200 \\
\hline \multirow[t]{3}{*}{ Students personal studies } & Pearson $r$ & $.536^{* *}$ & $.560^{* *}$ & & $.312 * *$ \\
\hline & Sig. (2-tailed) & .000 & .000 & & .000 \\
\hline & $\mathrm{N}$ & 200 & 200 & & 200 \\
\hline \multirow[t]{3}{*}{ Students' final grade points } & Pearson $r$ & $.414^{* *}$ & $.251^{* *}$ & $.312 * *$ & \\
\hline & Sig. (2-tailed) & .000 & .000 & .000 & \\
\hline & $\mathrm{N}$ & 200 & 200 & 200 & \\
\hline
\end{tabular}

Table 1 shows that at 0.05 alpha level, the relationship between continuous assessment practices and students personal studies is positive and significant $(\mathrm{r}=0.54, \mathrm{p} \leq .00)$. The relationship between continuous assessment practices and students' final grade is positive and significant $(\mathrm{r}=0.41, \mathrm{p} \leq .00)$. The relationship between continuous assessment practices and teaching effectiveness is positive and significant $(\mathrm{r}=0.67, \mathrm{p} \leq .00)$. The relationship between students' personal studies and teaching effectiveness is positive and significant $(\mathrm{r}=0.56, \mathrm{p} \leq 0.00)$. The relationship between teaching effectiveness and students' final grade is positive and significant $(r=0.25, p \leq 0.00)$. And the relationship between students personal studies and students' final grade is positive and significant $(r=0.31, p \leq 0.00)$.

\section{Hypothesis 2}

The multiple regression model of continuous assessment practices, teaching effectiveness and students' personal academic studies does not significantly predict students' final grades. The summary of the analysis of data in respect of this hypothesis is presented in Table 2. 
Predicting students' final grades for regulating the supervision of academic activities: A model of continuous assessment practices, teaching effectiveness and students' personal studies

Table 2: Multiple Regression Coefficient of Prediction of Students' Final Grades Using Ratings of (1) Continuous Assessment Practices, (2) Teaching Effectiveness, (3) Students' Personal Academic Studies

\begin{tabular}{|c|c|c|c|c|c|c|c|c|}
\hline $\mathbf{R}$ & R Square & $\begin{array}{c}\text { Adjusted R } \\
\text { Square }\end{array}$ & $\begin{array}{c}\text { Std } \\
\text { Error }\end{array}$ & $\begin{array}{c}\text { Sum of } \\
\text { Squares }\end{array}$ & df & $\begin{array}{l}\text { Mean } \\
\text { Square }\end{array}$ & $\mathbf{F}$ & Sig. \\
\hline .812 & .66 & .65 & 1.68 & $\begin{array}{l}\text { (1) } 169.10 \\
\text { (1) } 552.90 \\
\text { (2) } 722.00\end{array}$ & $\begin{array}{c}3 \\
196 \\
199 \\
\end{array}$ & $\begin{array}{c}56.37 \\
2.82\end{array}$ & 19.98 & .000 \\
\hline
\end{tabular}

Table 2 shows that at 0.05 alpha level, the multiple regression coefficient of the model of continuous assessment practices, teaching effectiveness and students' personal academic studies for predicting the students' final grade is positive and significant $(\mathrm{R}=0.65, \mathrm{p} \leq 0.00)$. The standard error between estimates and the actual values is 1.68 .

\section{Hypothesis 3}

The individual coefficients of continuous assessment practices, teaching effectiveness and students' personal studies in the multiple regression model does not significantly predict students' final grades. The summary of the analysis of data in respect of this hypothesis is presented in Table 3.

Table 3: Individual Coefficients of Prediction of Students' Final Grades Using Ratings of Continuous Assessment Practices, Teaching Effectiveness, and Students' Personal Studies.

\begin{tabular}{|c|c|c|c|c|c|}
\hline \multirow[b]{2}{*}{ Model } & \multicolumn{2}{|c|}{ Unstandardized Coefficients } & \multirow{2}{*}{$\begin{array}{c}\text { Standardized } \\
\text { Coefficients }\end{array}$} & \multirow[b]{2}{*}{$\mathbf{t}$} & \multirow[b]{2}{*}{ Sig. } \\
\hline & B & Std. Error & & & \\
\hline (Constant) & 2.244 & 1.093 & & 2.052 & .041 \\
\hline Continuous assessment practices & .540 & .063 & .538 & 6.145 & .000 \\
\hline Teaching effectiveness & .41 & .023 & .463 & .708 & .000 \\
\hline Students personal academic studies & .31 & .029 & .310 & 3.967 & .000 \\
\hline
\end{tabular}

Table 3 shows that at 0.05 alpha level, the individual coefficient of continuous assessment practices in the multiple regression model for predicting the students' final grades is positive and significant $(B=0.54, p$ $\leq 0.00$ ) while the individual coefficient of students' personal studies in the multiple regression model for predicting the students' final grades is positive and significant $(\mathrm{B}=0.31, \mathrm{P} \leq 0.00)$. And the individual coefficient of teaching effectiveness in the multiple regression model for predicting the students' final grades is positive and significant at 0.05 alpha level $(B=0.41, \mathrm{p} \leq 0.00)$.

\section{SUMMARY OF FINDINGS}

The major findings of this study are as follows:

1. The relationship between continuous assessment practices and students' final grade is positive and significant $(\mathrm{r}=0.41, \mathrm{p} \leq .00)$.

2. The relationship between continuous assessment practices and students' personal studies is positive and significant $(\mathrm{r}=0.54, \mathrm{p} \leq .00)$

3. The relationship between continuous assessment practices and teaching effectiveness is positive and significant $(\mathrm{r}=0.67, \mathrm{p} \leq .00)$.

4. The relationship between students' personal studies and teaching effectiveness is positive and significant $(\mathrm{r}=0.56, \mathrm{p} \leq 0.00)$.

5. The relationship between teaching effectiveness and students' final grade is positive and significant $(\mathrm{r}=0.25, \mathrm{p} \leq 0.00)$.

6. The relationship between students personal studies and students' final grade is positive and significant $(\mathrm{r}=0.31, \mathrm{p} \leq 0.04)$.

7. The multiple regression coefficient of prediction of students' final grade with ratings of continuous assessment practices, teaching effectiveness and students' personal academic studies 
is positive and significant $(\mathrm{R}=0.65, \mathrm{p} \leq 0.00)$.

8. The individual coefficient of continuous assessment practices in the prediction of students final grades is positive and significant $(\mathrm{B}=0.54, \mathrm{p} \leq 0.00)$.

9. The individual coefficient of students' personal studies in the prediction of students final grades is positive and significant $(\mathrm{B}=0.31, \mathrm{P} \leq 0.00)$.

10. The individual coefficient of teaching effectiveness in the prediction of students' final grades is positive and significant at 0.05 alpha level ( $\mathrm{B}=0.46, \mathrm{p} \leq 0.48$ )

\section{DISCUSSION OF FINDINGS}

On the predictive validity of the continuous assessment practices scale, the first finding of this study reveals that there is significant relationship between continuous assessment practices and students' personal academic studies. These findings are in agreement with that of Laurent (2011) who conducted a research on the influence of continuous assessment practices on students' academic performance. He found significant relationship among continuous assessment practices, high performance and analytical stills as result of time devoted by students on personal academic studies and regular practical exercises. On the contrary the researcher found out that the students from the low performing secondary schools were neither assessed continually nor engaged on practical work and students' personal academic studies were low. This according to him hampered the students' development of analytical stills.

With respect to the predictive validity of the teaching effectiveness scale, the findings of the study show that there is significant relationship between continuous assessment practices and quality of teachers' instructional presentations of subject matter. This research is in agreement with the findings of Joe, (2010) whose findings shown that students performed well in their subjects because of the continuous assessment practices, teaching effectiveness and teaching aids which make learning real and permanent. Thus Joe (2010) affirmed that teaching effectiveness play a vital role in students' academic performance in secondary schools.

The predictive validity of students' personal academic studies scale was also established in this study. The findings of the study show that there is significant relationship between students' personal academic studies and their final grades. Final grades are the summative of students' performance which comprise the continuous assessment and students' final examination. The students' final grade gives an idea of what impact the subject matter has on students, the evidence that the instructional objectives have been achieved. This finding was in agreement with Shoukat et al. (2013) who found that tutorials are the most important factors affecting the students' scores. The correlation strength among test scores and study hour and tutorials according to them, are positive and significant. This study is also supported by the work of Arribas (2012) which showed that high success rates in the continuous assessment are associated with the final results. Nevertheless Hau \& Wang (2013) showed that there is a negative impact of intense continuous assessment practices on students learning in English studies as students resort to memorization of words instead of in-depth learning and the students who failed the tests are psychologically distracted.

\section{CONCLUSION}

This study shows that, the model of continuous assessment practices, teaching effectiveness and students' personal studies collectively and individually predicts significantly students' final score with more confidence and administrative value as it would give specific clues for the supervision of academic activities.

\section{RECOMMENDATION}

Based on the findings of this study, it was, therefore, recommended that the ministry of education and school administrators adopt the model of continuous assessment practices, teaching effectiveness and students' personal studies to predict students' final grades, for regulating the supervision of teaching and learning process for optimization of students' academic achievement. 
Predicting students' final grades for regulating the supervision of academic activities: A model of continuous assessment practices, teaching effectiveness and students' personal studies

\section{REFERENCES}

Arribas, J.M.(2012).Academic performance in terms of the applied assessment system. Educational Research Assessment Evaluation, 18:1-14.

Federal Ministry of Education (2004). Handbook on continuous assessment. Lagos: Evaluation unit, Ministry of Education.

Federal Republic of Nigeria (1981). National policy on education, Lagos: Federal ministry of education

Federal Republic of Nigeria (1983). National policy on education. Lagos: Nigeria Educational Research and Development Council (NERDC).

Federal Republic of Nigeria (2013). National policy on education. Abuja. NERDC.

Hau H. \& Wang W. (2013). A study of formative assessment of ELF in the multimedia-based environment in China. International Journal of Assessment and Evaluation in Education, 3,1-14.

Joe, E. (2010). The Effect of Continuous Assessment on Academics Performance. Retrieved from /iproject.com.ng/order-project/pr/u3vtldr8g4p/order.html.

Kaddam, L. \& Elnimeiri, M.K. (2013).Students' perceptions about the impact of continuous assessment in learning physiology in Sudanese Faculty of medicine and health sciences. International Journal Education Research Development, 2,228-232.

Kellaghan, T, \& Greaney, V. (2003).Monitoring performance: Assessment and examination in Africa .Washington DC: World Bank.

Laurent, J. (2011). The influence of continuous assessment on students' academic performance in chemistry for ordinary level secondary education in Tanzania. Being a Dissertation Submitted in Partial Fulfillment of the Requirement for the Degree of Master of Education (Science Education) of the University of Dares Salaam.

Mwebaza, M. (2010) Continuous assessment and students performance in 'A' level secondary scools in masaka district. Master Thesis.

Obanya, P. (1985).Teaching methods across the curriculum. Worcester: Billing and Sons Ltd, UK.

Onuka, A. (2006).Continuous assessment as an instrument of achieving learning objectives. Unpublished Research Report, University of Ibadan.

Rezigalla, A.A, Abdalla, A.M, Haider, S.J., Ali, Q.M.,\& Alhassen, M.M. (2014).The impact of continuous assessment on the final results a case study: Sudan Medical Journal: College of medicine, King Khailid University., 9:149-52.

Shoukat, A., Zurbar, Faha, H., Hamid, A. \& Awais, Z. (2013). Factors contributing to the students' academic performance: A case study of Ismalia University Sub-campus. American Journal of Research 2,22-26.

Trottera, E. (2006).Student perceptions of continuous summative assessment assess evaluation high education. Journal of Education 31(1):505-21.

Webb, N., \& Barries, D. (1990). Assessment in mathematics classroom, K-8. In T.J Cooney (ed). Teaching and learning mathematics in the 1990s, 1990 Yearbook of the National council of teachers of mathematics Reston VA.

Yamane, T. (1967). Statistics: An introductory analysis (2nd Ed.). New York: Harper and Row. 